\title{
Constitución Apostólica Vultum Dei quaerere, sobre la vida contemplativa femenina, de 29 de junio de 2016 (Introducción y parte dispositiva)*
}

Sumo Pontífice Francisco

1. La búsqueda del rostro de Dios atraviesa la historia de la humanidad, llamada desde siempre a un diálogo de amor con el Creador ${ }^{1}$. El hombre y la mujer, en efecto, tienen una dimensión religiosa indeleble que orienta su corazón hacia la búsqueda del Absoluto, hacia Dios, de quien perciben la necesidad, aunque no siempre de manera consciente. Esta búsqueda es común a todos los hombres de buena voluntad. Y muchos que se profesan no creyentes confiesan este anhelo profundo del corazón, que habita y anima a cada hombre y a cada mujer deseosos de felicidad y plenitud, apasionados y nunca saciados de gozo.

En las Confesiones, san Agustín lo ha expresado con claridad: «Nos hiciste Señor para ti y nuestro corazón está inquieto hasta que no descanse en ti» ${ }^{2}$. Inquietud del corazón que brota de la intuición profunda de que es Dios el que busca primero al hombre, atrayéndolo misteriosamente a sí.

La dinámica de la búsqueda manifiesta que nadie se basta a sí mismo e impone encaminarse, a la luz de la fe, por un éxodo del propio yo auto-centrado, atraídos por el rostro de Dios santo, y al mismo tiempo por la «tierra sagrada del otro» ${ }^{3}$, para experimentar una comunión más profunda.

Esta peregrinación en busca del Dios verdadero, que es propio de cada cristiano y de cada consagrado por el Bautismo, se convierte por la acción del

\footnotetext{
* Texto tomado de www.vatican.va.

1 Cfr. Conc. Ecum. Vat. II, Const. past. Gaudium et spes, 19.

${ }^{2}$ I, 1, 1: PL 32, 661.

${ }^{3}$ Cfr. Exhort. ap. Evangelii gaudium (24 de noviembre de 2013), 169: AAS 105 (2013) 1091.
} 
Espíritu Santo en sequelapressius Christi, camino de configuración a Cristo Señor, que la consagración religiosa expresa con una singular eficacia y, en particular, la vida monástica, considerada desde los orígenes como una forma particular de actualizar el Bautismo.

2. Las personas consagradas, quienes por la consagración «siguen al Señor de manera especial, de modo profético» ${ }^{4}$, son llamadas a descubrir los signos de la presencia de Dios en la vida cotidiana, a ser sapientes interlocutores capaces de reconocer los interrogantes que Dios y la humanidad nos plantean. Para cada consagrado y consagrada el gran desafío consiste en la capacidad de seguir buscando a Dios «con los ojos de la fe en un mundo que ignora su presencia» ${ }^{5}$, volviendo a proponer al hombre y a la mujer de hoy la vida casta, pobre y obediente de Jesús como signo creíble y fiable, llegando a ser de esta forma, «exégesis viva de la Palabra de Dios» ${ }^{\circ}$.

Desde el nacimiento de la vida de especial consagración en la Iglesia, hombres y mujeres, llamados por Dios y enamorados de él, han vivido su existencia totalmente orientados hacia la búsqueda de su rostro, deseosos de encontrar y contemplar a Dios en el corazón del mundo. La presencia de comunidades situadas como ciudad sobre el monte y lámpara en el candelero (cfr. Mt 5,14-15), en su misma sencillez de vida, representa visiblemente la meta hacia la cual camina toda la comunidad eclesial que «se encamina por las sendas del tiempo con la mirada fija en la futura recapitulación de todo en Cristo $^{7}$, preanunciando de este modo la gloria celestial» ${ }^{8}$.

3. Si para todos los consagrados adquieren una particular resonancia las palabras de Pedro: «Señor, iqué bueno es estar aquí!» (Mt 17,4), las personas contemplativas, que en honda comunión con todas las otras vocaciones de la vida cristiana «son rayos de la única luz de Cristo que resplandece en el rostro de la Iglesia $»^{9}$, «por su carisma específico dedican mucho tiempo de la jor-

${ }^{4}$ Carta ap. A todos los consagrados con ocasión del Año de la Vida Consagrada (21 de noviembre de 2014), II, 2: AAS 106 (2014) 941.

5 JUAN PABLO II, Exhort. ap. postsinodal Vita consecrata (25 de marzo de 1996), 68: AAS 88 (1996) 443.

${ }^{6}$ Benedicto XVI, Exhort. ap. postsinodal Verbum Domini (30 de septiembre de 2010), 83: AAS $102(2010) 754$.

7 JUAN PABLO II, Exhort. ap. postsinodal Vita consecrata (25 de marzo de 1996), 59: AAS 88 (1996) 432.

${ }^{8}$ Cfr. $C I C$ c. $573 / 1$.

9 JUAN Pablo II, Exhort. ap. postsinodal Vita consecrata (25 de marzo de 1996), 16: AAS 88 (1996) 389. 
nada a imitar a la Madre de Dios, que meditaba asiduamente las palabras y los hechos de su Hijo (cfr. Lc 2,19.51), así como a María de Betania que, a los pies del Señor, escuchaba su palabra (cfr. Lc 10,38) ${ }^{10}$. Su vida «escondida con Cristo en Dios» (cfr. Col 3,3) se convierte así en figura del amor incondicional del Señor, el primer contemplativo, y manifiesta la tensión teocéntrica de toda su vida hasta poder decir con el Apóstol: «Para mí vivir es Cristo» (Flp 1,21), y expresa el carácter totalizador que constituye el dinamismo profundo de la vocación a la vida contemplativa ${ }^{11}$.

Como hombres y mujeres que habitan la historia humana, los contemplativos atraídos por el fulgor de Cristo, «el más hermoso de los hijos de los hombres» (Sal 45,3), se sitúan en el corazón mismo de la Iglesia y del mundo ${ }^{12} y$, en la búsqueda inacabada de Dios, encuentran el principal signo y criterio de la autenticidad de su vida consagrada. San Benito, padre del monaquismo occidental, subraya que el monje es aquel que busca a Dios por toda la vida, y en el aspirante a la vida monástica pide que se compruebe si revera Deum quaerit, si busca verdaderamente a Dios ${ }^{13}$.

En particular, un número incontable de mujeres consagradas, a lo largo de los siglos y hasta nuestros días, han orientado y siguen orientando «toda su vida y actividad a la contemplación de Dios» ${ }^{14}$, como signo y profecía de la Iglesia virgen, esposa y madre; signo vivo y memoria de la fidelidad con que Dios sigue sosteniendo a su pueblo a través de los eventos de la historia.

4. Elemento de unidad con las otras confesiones cristianas ${ }^{15}$, la vida monástica se configura según su propio estilo que es profecía y signo, y que «debe atraer eficazmente a todos los miembros de la Iglesia a cumplir sin desfallecimiento los deberes de la vida cristiana» ${ }^{16}$. Las comunidades de orantes y, en particular, las comunidades contemplativas, «que con su separación del mundo

${ }^{10}$ Benedicto XVI, Exhort. ap. postsinodal Verbum Domini (30 de septiembre de 2010), 83: AAS $102(2010) 754$.

11 Cfr. Juan Pablo II, Exhort. ap. postsinodal Vita consecrata (25 de marzo de 1996), 18: AAS 88 (1996) 391-392.

12 Cfr. Conc. Ecum. Vat. II, Const. dogm. Lumen gentium, 44; Juan Pablo II, Exhort. ap. postsinodal Vita consecrata (25 de marzo de 1996), 3.29: AAS 88 (1996) 379-402.

13 Regla 58, 7.

14 JUAN PABLO II, Exhort. ap. postsinodal Vita consecrata (25 de marzo de 1996), 8: AAS 88 (1996) 382-383.

15 IDEM, Carta ap. Orientale lumen (2 de mayo de 1995), 9: AAS 87 (1995) 754.

${ }^{16}$ Conc. Ecum. VAT. II, Const. dogm. Lumen gentium, 44. 
se encuentran más íntimamente unidos a Cristo, corazón del mundo» ${ }^{17}$, no proponen una realización más perfecta del Evangelio sino que, actuando las exigencias del Bautismo, constituyen una instancia de discernimiento y convocación al servicio de toda la Iglesia: signo que indica un camino, una búsqueda, recordando al pueblo de Dios el sentido primero y último de lo que él vive ${ }^{18}$.

(...)

\section{ConCluSIón DISPOSITIVA}

A la luz de lo considerado hasta aquí, dispongo y establezco lo que sigue:

Art. 1

Conforme al c. 20 del CIC y tras haber considerado con mucha atención los 37 artículos que preceden, por la promulgación y publicación de esta Constitución Apostólica Vultum Dei quaerere quedan derogados:

1. Los cánones del CIC que, en parte, resulten directamente contrarios a cualquier artículo de la presente Constitución;

2. y, más en particular, los artículos dispositivo-normativos:

- de la Constitución Apostólica Sponsa Christi de Pío XII de 1950: Estatuta generalia Monialium;

- de la Instrucción Inter praeclara de la Sagrada Congregación de Religiosos;

- de la Instrucción Verbi Sponsa, de la CIVCSVA, 13 de mayo de 1999, sobre la vida contemplativa y la clausura de las monjas.

Art. 2

$\$ 1$. Esta Constitución se dirige a la Congregación para los Institutos de Vida Consagrada y las Sociedades de Vida Apostólica y a los monasterios femeninos de vida contemplativa o integralmente contemplativa, federados o no federados.

$\$ 2$. Son materias reguladas por esta Constitución Apostólica las enumeradas arriba en el n. 12 y desarrolladas en los números 13-35.

17 BenEdicto XVI, Exhort. ap. postsinodal Verbum Domini (30 de septiembre de 2010), 83: AAS $102(2010) 754$.

${ }^{18}$ Cfr. Conc. Ecum. Vat. II, Decr. Perfectae caritatis, 5. 
$\$ 3$. La Congregación para los Institutos de Vida Consagrada y las Sociedades de Vida Apostólica -en caso de que sea necesario de acuerdo con la Congregación para las Iglesias Orientales o la Congregación para la Evangelización de los Pueblos- reglamentará las distintas modalidades de actuación de estas normas constitutivas, según las diversas tradiciones monásticas y teniendo en cuenta las diferentes familias carismáticas.

\section{Art. 3}

$\$ 1$. Cada monasterio cuide con particular esmero, por medio de oportunas estructuras, la elaboración del proyecto de vida comunitaria, la formación permanente, que es como el bumus de cada una de las etapas de la formación, ya a partir de la inicial.

$\$ 2$. Con el fin de asegurar una adecuada formación permanente, las federaciones promuevan la colaboración entre los monasterios por medio de intercambio de material formativo y el uso de medios de comunicación digital, salvaguardando siempre la necesaria discreción.

$\$ 3$. Además del cuidado en elegir a las hermanas llamadas como formadoras a acompañar a las candidatas por el camino de la madurez personal, cada uno de los monasterios y las federaciones promuevan la formación de las formadoras y de sus colaboradoras.

$\$ 4$. Las hermanas llamadas a ejercer el delicado servicio de la formación pueden, servatis de iure servandis, participar en cursos específicos de formación aunque sea fuera de su monasterio, manteniendo un clima adecuado y coherente con las exigencias del propio carisma. La Congregación para los Institutos de Vida Consagrada y las Sociedades de Vida Apostólica promulgará al respecto normas particulares.

$\$ 5$. Los monasterios prestarán especial atención al discernimiento espiritual y vocacional, asegurarán a las candidatas un acompañamiento personalizado y promoverán itinerarios formativos adecuados, considerando siempre que hay que reservar un amplio espacio de tiempo a la formación inicial.

$\$ 6$. Aunque la constitución de comunidades internacionales y multiculturales ponga de manifiesto la universalidad del carisma, hay que evitar en modo absoluto el reclutamiento de candidatas de otros países con el único fin de salvaguardar la supervivencia del monasterio. Que se elaboren criterios para asegurar que esto se cumpla. 
$\$ 7$. Para asegurar una formación de calidad, según las circunstancias, promuévanse casas de formación inicial comunes entre varios monasterios.

\section{Art. 4}

$\$ 1$. Considerando que la oración es el corazón de la vida contemplativa, que cada monasterio verifique el ritmo de la propia jornada para evaluar si el Señor es su centro.

$\$ 2$. Se evaluarán las celebraciones comunitarias, preguntándose si son realmente un encuentro vivo con el Señor.

\section{Art. 5}

$\$ 1$. Por la importancia que la lectio divina reviste, que cada monasterio establezca tiempos y modalidades oportunos para esta exigencia de lectura/ escucha, ruminatio, oración, contemplación y puesta en común de las Sagradas Escrituras.

$\$ 2$. Considerando que el compartir la experiencia transformante de la Palabra con los sacerdotes, los diáconos, los demás consagrados y los laicos es expresión de verdadera comunión eclesial, cada monasterio verá cuáles pueden ser las modalidades de esta irradiación espiritual ad extra.

\section{Art. 6}

$\$ 1$. En la elaboración del proyecto comunitario y fraterno, además de la preparación con esmero de la celebración eucarística, que cada monasterio prevea tiempos convenientes de adoración eucarística, ofreciendo también a los fieles de la Iglesia local la posibilidad de participar en ellos.

$\$ 2$. Cuídese en particular la elección de capellanes, confesores y directores espirituales, considerando la especificidad del carisma propio y las exigencias de la vida fraterna en comunidad.

\section{Art. 7}

$\$ 1$. Quienes son llamadas a ejercer el ministerio de la autoridad, además de cuidar de su propia formación, sean guiadas por un real espíritu de fraternidad y de servicio, para favorecer un clima gozoso de libertad y de responsa- 
bilidad para promover el discernimiento personal y comunitario y la comunicación en la verdad de lo que se hace, se piensa y se siente.

$\$ 2$. El proyecto comunitario acoja con agrado y aliente el intercambio de dones humanos y espirituales de cada hermana, para el mutuo enriquecimiento y el progreso de la fraternidad.

\section{Art. 8}

$\$ 1$. A la autonomía jurídica ha de corresponder una real autonomía de vida, lo cual significa: un número aunque mínimo de hermanas, siempre que la mayoría no sea de avanzada edad; la necesaria vitalidad a la hora de vivir y transmitir el carisma; la capacidad real de formación y de gobierno; la dignidad y la calidad de la vida litúrgica, fraterna y espiritual; el significado y la inserción en la Iglesia local; la posibilidad de subsistencia; una conveniente estructura del edificio monástico. Estos criterios han de considerarse en su globalidad y en una visión de conjunto.

$\$ 2$. Cuando no subsistan los requisitos para una real autonomía de un monasterio, la Congregación para los Institutos de Vida Consagrada y las Sociedades de Vida Apostólica estudiará la oportunidad de constituir una comisión ad boc formada por el Ordinario, por la Presidenta de la federación, por el Asistente federal y por la Abadesa o Priora del monasterio. En todo caso, dicha intervención tenga como fin actuar un proceso de acompañamiento para revitalizar el monasterio, o para encaminarlo hacia el cierre.

$\$ 3$. Este proceso podría prever también la afiliación a otro monasterio o confiarlo a la Presidenta de la federación, si el monasterio es federado, con su Consejo. En todo caso, la decisión última corresponde a la Congregación para los Institutos de Vida Consagrada y las Sociedades de Vida Apostólica.

\section{Art. 9}

$\$ 1$. En principio, todos los monasterios han de formar parte de una federación. Si por razones especiales un monasterio no pudiera ser federado, con el voto del capítulo, pídase permiso a la Santa Sede, a la que corresponde realizar el oportuno discernimiento, para consentir al monasterio no pertenecer a una federación.

$\$ 2$. Las federaciones podrán configurarse no tanto y no sólo según un criterio geográfico, sino de afinidades de espíritu y tradiciones. Las modalida- 
des al respecto serán indicadas por la Congregación para los Institutos de Vida Consagrada y las Sociedades de Vida Apostólica.

$\$ 3$. Se garantizará, asimismo, la ayuda en la formación y en las necesidades concretas por medio de intercambios de monjas y la puesta en común de bienes materiales, según como disponga la Congregación para los Institutos de Vida Consagrada y las Sociedades de Vida Apostólica, que además establecerá las competencias de la Presidenta y del Consejo de Federación.

$\$ 4$. Se favorecerá la asociación, también jurídica, de los monasterios con la Orden masculina correspondiente. Se favorecerán también las Confederaciones y la constitución de Comisiones internacionales de varias Órdenes, con estatutos aprobados por la Congregación para los Institutos de Vida Consagrada y las Sociedades de Vida Apostólica.

\section{Art. 10}

$\$ 1$. Tras un serio discernimiento, y respetando la propia tradición y lo que exigen las Constituciones, cada monasterio pida a la Santa Sede qué forma de clausura quiere abrazar, si es que pide una forma diversa a la que tiene vigor.

$\$ 2$. Una vez que se ha optado por una de las formas de clausura previstas, y que ésta haya sido aprobada, que cada monasterio se esmere en seguirla y viva según lo que conlleva.

\section{Art. 11}

$\$ 1$. Aunque algunas comunidades monásticas pueden tener rentas, según el derecho propio, sin embargo no se eximan del deber de trabajar.

$\$ 2$. Para las comunidades dedicadas a la contemplación, que el fruto del trabajo no sea sólo para asegurar un sustento digno, sino que también y en la medida de lo posible tenga como fin socorrer las necesidades de los pobres y de los monasterios necesitados.

\section{Art. 12}

El ritmo cotidiano de cada monasterio prevea oportunos momentos de silencio, para favorecer el clima de oración y de contemplación. 


\section{Art. 13}

Cada monasterio prevea en su proyecto comunitario los medios idóneos por los que se expresa el compromiso ascético de la vida monástica, para que sea más profética y creíble.

\section{Disposición final}

\section{Art. 14}

$\$ 1$. La Congregación para los Institutos de Vida Consagrada y las Sociedades de Vida Apostólica promulgará una nueva Instrucción sobre las materias consideradas en el n. 12, y lo hará según el espíritu y las normas de esta Constitución Apostólica.

$\$ 2$. Los artículos de las Constituciones o Reglas de cada uno de los Institutos, una vez que se hayan adaptado a las nuevas disposiciones, tendrán que someterse a la aprobación de la Santa Sede.

Dado en Roma junto a san Pedro, el día 29 de junio, solemnidad de los santos Pedro y Pablo, del año 2016, cuarto de mi pontificado.

\section{FRANCISCO}


